\title{
A MODEL FOR UNDERSTANDING THE PROCESSES, CHARACTERISTICS, AND THE COMMUNITY-VALUED DEVELOPMENT OUTCOMES OF COMMUNITY-UNIVERSITY PARTNERSHIPS
}

\author{
Mary Sweatman and Alan Warner
}

\section{Abstract}

The research investigates the processes and characteristics of community-valued undergraduate community service-learning (CSL) initiatives that are housed within long-term community-university partnerships (CUPs). Using a case study design, the study used in-depth, semi-structured interviews, document review, and observation to understand three CSL/CUPs within a small, liberal arts university in Atlantic Canada. In total, 54 interviews were conducted with individuals involved with the partnerships, including the community organization partners, staff/volunteers of the community organizations, community residents, students, faculty, and university administrators. Part of the analysis process involved co-writing the stories of each of the CSL/CUPs with the community organization partner and the faculty member partner from each CSL/CUP. From the three CSL/CUP stories and current literature, a conceptual model was developed. This model depicts the processes (development, co-creation, implementation, and care) and key characteristics (reciprocity, dialogue, and praxis) of long-term CUPs that are committed to a shared domain and community-valued development outcomes.

\section{Introduction}

Community service-learning (CSL) that is valued by the community has been found to be situated within a community-university partnership (CUP) (Bringle, Clayton, \& Price, 2009; Oberg De La Garza \& Moreno Kuri, 2014; Rosing \& Hofman, 2010). CSL within a CUP (CSL/CUP) are collaborations between communitybased organizations and universities that work toward identified goals through mutually beneficial practices and outcomes (Eckerle Curwood, Munger, Mitchell, Mackeigan, \& Farrar, 2011). The majority of the research on the impacts of CSL/CUPs has focused on students and their developmental experiences (see Astin, Vogelgesang, 
Ikeda, \& Yee, 2000; Kearney, 2013; Srinivas, Meenan, Drogin, \& DePrince, 2015); however, many scholars agree that more research is needed to understand the CSL/CUP and its potential for community-valued development outcomes (Bargerstock \& Bloomgarden, 2015; Chupp \& Joseph, 2010; Eckerle Curwood et al., 2011; Gerstenblatt \& Gilbert, 2014). In a recent call for more empirical research on community engagement, Bloomgarden (2017) stated that "inquiry into and scholarship about where, how, when, and why campus-community engagement does or does not contribute to or facilitate community-valued development outcomes that are systemic and sustainable is woefully thin" (para. 2). For this study, community-valued development outcomes are defined as the impacts, resulting from the co-creation of knowledge between the partners involved in the CSL/CUP, that benefit the community-based organization and influence community development.

The present study was designed to address Bloomgarden’s (2017) call by investigating three long-term CSL/ CUPs that facilitate community-valued development outcomes at a small, undergraduate university in Atlantic Canada. The guiding research question was, What are the processes and characteristics of long-term CSL/CUPs that contribute to community-valued development outcomes?

In order to address this research question, this article begins with a brief literature review on the processes, characteristics, and outcomes of community-university partnerships. A description of the study's methods follows, which leads into three vignettes that describe the premise of each of the three CSL/CUP examples in this study and their community-valued development outcomes. The analysis and discussion section presents a conceptual model developed from the literature review and CSL/CUP examples, defining processes and characteristics of CSL/CUPs that result in community-valued development outcomes. Finally, this article concludes with the implications of this study for future research and practice.

\section{Research on Processes, Characteristics, and Outcomes of Community-University Partnerships}

This brief literature review highlights what is already known about the processes, characteristics, and outcomes of CSL/CUPs and concludes with recommendations to investigate them more holistically.

\section{Processes}

Processes refer to the steps in which the CSL/CUP progresses from beginning to end. Suarez-Balcazar, Harper, and Lewis (2005) developed an interactive and conceptual model depicting the process of developing and sustaining community partnerships, which originated from a study between a nonprofit community organization and a university research team involving graduate students. It provides a framework for understanding the process of CUPs: gaining entry into the community, the complex components of developing and sustaining the relationship, the potential challenges and threats to the partnership, and the potential benefits and outcomes. Before such complex partnerships are initiated, Eckerle Curwood et al. (2011) recommend that a university needs to ensure they are ready to engage in a long-term collaborative process. To facilitate this process, Eckerle Curwood 
et al. developed a set of 10 questions that should be asked before and during the formative stages of the CUP. Both of the above studies used community-oriented and participatory research methods to engage community authentically in their initiatives. Many other CSL studies also use a community-engaged research process, which integrates assessment and evaluation into the projects, increasing academic rigor and accountability to the community (Dunkel, Shams, \& George, 2011; Hlalele, Manicom, Preece, \& Tsotetsi, 2015; Howard, 2010; Rutherford, Walsh, \& Rook, 2011; Weaver et al., 2017).

\section{Characteristics}

The characteristics of a CSL/CUP refers to the distinguishing features of the partnership. Partnerships can be characterized as transactional or transformational (Enos \& Morton, 2003). Transactional relationships are project based and require limited commitment and minimal disruption to the community partner, whereas transformative relationships are long-term and require deep reflection and openness to change (Shalabi, 2013). The difference between the two is similar to Saltmarsh, Hartley, and Clayton's (2009) distinction between civic engagement and democratic civic engagement. Civic engagement, characterized by activity and place, is based on academic work for the community, with knowledge flowing from the institution to the community. Democratic civic engagement, characterized by purpose and process, is based on academic work done with the public, with a multi-directional flow of knowledge.

Similarly, Janke, and Clayton (2012) believe that CSL/CUPs should be characterized by reciprocal processes and public purposes of the collaboration. They define reciprocal processes as "recognizing, respecting and valuing the knowledge, perspective, and resources that each partner contributes to the collaboration," whereas public purposes are "building the capacity of each of the individuals, groups, and organizations involved to understand and collaboratively address issues of public concern” (p. 3). Gazley, Bennett, and Littlepage (2013) found that reciprocity is a key characteristic that must begin in the planning stages of the partnership and continue through to student evaluations. Reciprocity goes beyond mutual benefit to power sharing through more equitable relationships, "being grounded in explicitly democratic values of sharing previously academic tasks with non-academics” (Saltmarsh et al., 2009, p. 9). Reciprocal relationships, however, are challenging to develop and maintain (Naidoo \& Devnarain, 2009) and require continuous vigilance regarding power dynamics between partners (Hlalele et al., 2015).

Reciprocity encompasses mutual trust and mutual respect (Janke, 2013), and these characteristics are highlighted in the literature as key to CSL/CUP success (Austin, 2010; Costandius, Rosochacki, \& le Roux, 2014; Rosing \& Hofman, 2010). A tangible way they are demonstrated by the faculty partner is through long-term investments that transcend the artificial time frame of the semester (Gerstenblatt \& Gilbert, 2014; Rosing \& Hofman, 2010; Rutherford et al., 2011; Wills, Chinemana, \& Rudolph, 2010).

The characteristics identified by the above studies either distinguish between different characteristics of CSL/ CUPs, such as transactional vs. transformative, or are case studies defining specific CSL/CUPs based on characteristics and how these are demonstrated. These studies add to the understanding of key characteristics of 
long-term community engagement, particularly demonstrating the importance of reciprocity as a key feature of CSL/CUPs.

\section{Outcomes}

To advance the field's understanding of community outcomes, Srinivas et al. (2015) developed a comprehensive Community Impact Scale (CIS) measuring the benefits and costs of CUPs from the community partner perspective. This scale identifies 46 domains of potential impacts on community partners. The costs and benefits can be tangible or intangible (Goemans, 2016). Important tangible benefits noted by many studies were access to the university and its resources, such as student-volunteers (Oberg De La Garza \& Moreno Kuri, 2014; Schaffer, Hargate, \& Marong, 2015; Valaitis et al., 2016). Similarly, many case studies reported that their CSL/CUP increased the assets of community members or the organization, such as participant health benefits, skill development, organizational capacity, and social integration (Apatu, Slawson, \& Gonzalez, 2013; Bucher, 2012; Costandius et al., 2014; Jovanović \& Filipović, 2013; Wilson, 2016). Tangible costs associated with CSL/ CUP outcomes include draining community and organizational resources for student training and supervision (Blouin \& Perry, 2009).

Intangible outcomes can include advancing the community's capacity to identify and address social and environmental issues and influence systemic change (Davidson, Jimenez, Onifade, \& Hankins, 2010; Shields, Gilchrist, Nixon, Holland, \& Thompson, 2013), strengthening community pride and empowerment (Pillard Reynolds, 2014; Srinivas et al., 2015), and enabling community members to speak their stories, particularly the “missing” stories of marginalized populations (Jamal, Taillon, \& Dredge, 2011; Shields et al., 2013). Intangible costs include feelings of frustration and mistrust due to lack of communication with faculty, lack of student commitment or knowledge, and lack of perceived faculty interest (Cronley, Madden, \& Davis, 2015; Shalabi, 2913; Worrall, 2007).

Avoiding community marginalization requires a co-created process. Saltmarsh et al. (2009) state that a democratic civic engagement framework based on purpose and process will produce community change outcomes that result from the co-creation of knowledge through a dialectical process. This process links to Paulo Freire's critical pedagogy, which is a foundational education philosophy that grounds this study as its theoretical framework (Gerstenblatt \& Gilbert, 2014). Freire (1993) theorized that a synthesis of action and reflection offers a way of building theory in order to understand the constantly changing contexts of one's practice, and in the case of this study, the practice is developing long-term CSL/CUPs (Ledwith, 2015). Freire is one of many theorists who have contributed to understanding social learning systems through his work on critical consciousness, dialogue, and praxis, which has influenced the community engagement field (Blackmore, 2010). Particularly, examining CSL/CUPs through the lenses of dialogue and praxis allows the investigation to focus on learning processes and systems of interaction in social contexts, with an emphasis on social transformation (Blackmore, 2010). The literature recognizes dialogue between partners as a key characteristic of CSL/CUPs (Gazley et al., 2013; Oberg 
De La Garza \& Moreno Kuri, 2014), as well as praxis (Stanlick \& Sell, 2016), which together with reciprocity are identified in the case study examples in this article as key overarching characteristics of CSL/CUPS.

The studies above demonstrate that much is known about the processes, characteristics, and outcomes of CSL/CUPs. However, the gaps in the research, which are articulated by Bloomgarden (2017), are studies that explore the holistic nature of CSL/CUPs by understanding how processes and characteristics interconnect and their subsequent impact on community-valued development outcomes.

\section{Methods}

Within a constructivist paradigm, ${ }^{1}$ the focus of this case study is on both describing the CSL/CUPs as well as illustrating the processes of CSL/CUPs that create community-valued development outcomes (Lauckner, Paterson, \& Krupa, 2012; Merriam, 2007; Stake, 1995). In this case study, the case is the CSL/CUP concept, which is understood by exploring three long-term, undergraduate CSL/CUPs at a small, rural, primarily undergraduate university that positions itself as committed to community engagement and student citizenship. In order to identify examples at Acadia University, the following eligibility criteria were adhered to:

1. The CSL/CUP is invested in a long-term relationship that transcends the artificial time frame of the semester (Gerstenblatt \& Gilbert, 2014; Rutherford et al., 2011; Shields et al., 2013).

2. The community organization partner and faculty partner of the CSL/CUP are invested in and accountable for community-valued development outcomes (Carney, Maltby, Mackin, \& Maksym, 2011; Gazley et al., 2013; Klein et al., 2011).

3. There is a mutual sharing of physical and human resources, which is a mark of a true partnership (Austin, 2010; Marullo, Moayedi, \& Cooke, 2009; Naidoo \& Devnarain, 2009).

4. Both the community organization partner and the university partner believe the CSL/CUP is beneficial to the community and students (Gazley et al., 2013; Oberg De La Garza \& Moreno Kuri, 2014; Valaitis et al., 2016).

5. The partners of the CSL/CUP are invested in mutual learning (Northmore \& Hart, 2011).

To identify CSL/CUPs that met these criteria, suggestions were sought from approximately 25 university participants (faculty, staff, and students) at a small symposium on community engagement. Participants at the symposium were asked to identify what they considered exemplary CSL/CUPs at the university. An email was sent to faculty who were identified as being engaged in these CSL/CUPs. Faculty who were interested in partic-

1. A constructivist paradigm assumes that what is real is constructed in the mind, and constructions can be extensively shared as collective or systematic in an effort to come to consensus or agreement on a state of affairs in an attempt to make sense of experience (Guba \& Lincoln, 1989; Prawat \& Floden, 1994; Schwandt, 1994). For the researcher, they cannot be disentangled from the research. The act of inquiry is therefore a discourse or dialogue of analysis and critique that eventually leads to a joint construction of the case (Lauckner, Paterson, \& Krupa, 2012; Stake, 2006). 
ipating in the study responded to this email, and subsequently initial meetings were arranged with the faculty member and the community organization partner to ensure the CSL/CUP met the study's criteria and to verify the partners' interest. Three CSL/CUPs who met the criteria agreed to participate in the study. The first CSL/ CUP is between one faculty member teaching a kinesiology elective course and the recreation director of the Wolfville Nursing Home, a local long-term care facility, and is referred to as the Aging Well CSL/CUP. The second CSL/CUP is between the director of the School of Nutrition and the local Wolfville Farmers' Market manager, and is referred to as the Farmers' Market CSL/CUP. The third CSL/ CUP is a university-wide initiative led by a faculty member in kinesiology and the local school board, which engages 17 local schools. It is called the Adapted Physical Activity CSL/CUP.

\section{Data Collection and Analysis}

In keeping with case study methodology (Merriam, 2007; Stake, 1995), this study took place over a three-year period and used in-depth, semi-structured interviews, document review, and observation to understand the CSL/CUPs. In total, 55 interviews were conducted with individuals involved with the partnership, including the community organization partner, staff/volunteers of the community organization, community residents, students, faculty and university administrators. The interviews were between 30 minutes and 90 minutes in length and took place in public settings, often at the location of the CSL initiative. Table 1 represents how many interviews were conducted for each CSL/CUP example.

The first stage of data collection involved a three-stage collaborative interview process with the community organization and faculty partners from each of the three CSL/CUPs. This involved an individual interview, a transcript review process, and then a follow-up interview that brought the CSL/CUP community organization partner and the faculty partner together to discuss their processes, characteristics, and outcomes. At the follow-up interview, the partners provided names of potential interviewees involved in the CSL/CUP as well as copies of documents that related to the CSL/CUP. Network selection strategy (Merriam, 2007) was then used each time an interview was conducted until each CSL/CUP was understood from multiple perspectives.

In addition to the interviews, the course syllabi and CSL assignment materials were reviewed for each CSL/ CUP, as well as any operational or evaluative material, such as manuals, websites, student reflections, and meet-

Table 1

Interviews Conducted for Each CSL/CUP and the Category of Interviewee

\begin{tabular}{lccccccc}
\hline $\begin{array}{l}\text { Interviewees/ } \\
\text { CUPs }\end{array}$ & $\begin{array}{c}\text { Comm. org. } \\
\text { partner }\end{array}$ & $\begin{array}{c}\text { Faculty } \\
\text { partner }\end{array}$ & $\begin{array}{c}\text { Comm. } \\
\text { members }\end{array}$ & $\begin{array}{c}\text { Comm. } \\
\text { org. staff }\end{array}$ & $\begin{array}{c}\text { University } \\
\text { staff/admin. }\end{array}$ & Students & Total \\
\hline Aging Well & 1 & 1 & 8 & 2 & 0 & 4 & 16 \\
Farmers' Market & 1 & 1 & 6 & 1 & 0 & 5 & 14 \\
Adapted Physical Activity & 1 & 1 & 6 & 3 & 1 & 7 & 19 \\
Involved in all three CUPs & 0 & 0 & 0 & 0 & 6 & 0 & 6 \\
Total & 3 & 3 & 20 & 6 & 7 & 16 & 55 \\
\hline
\end{tabular}


ing notes. These documents were analyzed to understand how the CSL/CUP was being described to students and the public, which contributed to a comprehensive description of the CSL/CUPs (Merriam, 2007). Onsite, direct observations were conducted on three to five program days for each initiative. During these observations, field notes were taken to add to a comprehensive understanding of the CSL/CUPs.

As interviews and field notes were completed and documents received, they were coded by indexing keywords and phrases that emerged from the data (Merriam, 2007). After documents were coded, they were grouped thematically by identifying themes within the codes, categorizing results (Krueger \& Casey, 2014; Merriam, 2007). For example, codes such as community passion, community interest, invested beyond job requirements were pulled together under the theme of social domain.

Throughout the three years of data collection and analysis, a reflective process was also developed by keeping extensive field notes that consisted of empirical details as well as sketches and free-writing about emerging thematic ideas. These practices maintained a clear audit trail of the research and allowed for introspection on the primary researcher's positionality, who has an insider perspective as a faculty member at the university under exploration (Simons, 2009).

\section{The Three CSL/CUP Examples}

Short vignettes for each of the three CSL/CUPs are below and are based on the data collected, which highlight their uniqueness and complexities, focusing on their development, processes, and characteristics. Each vignette also provides evidence of the community-valued development outcomes as perceived by the community partners and participants. These short narratives are provided relative to a more traditional presentation of participant quotes because they seemed better able to distill the large amount of data efficiently into descriptions that provide insights from the CSL/CUPs. The stories were written using data from the CSL/CUP interviews and then cross-referenced with the themes that emerged from the coding process. The main partners in each of the CSL/CUPs provided extensive input on their CSL/CUP story throughout the writing, and they approved the final version. They also gave consent to use their names and places of work.

\section{Example 1: Aging Well CSL/CUP-service and friendship at a long-term care facility}

When Professor Ann Dodge from the School of Kinesiology began teaching a course called Wellness and Aging, she contacted Margaret Coghill, the recreation director at the Wolfville Nursing Home, a local long-term care facility, to inquire about service-learning opportunities. Margaret agreed to develop a practicum with Ann for this course because she understood the impact this could have on her programming capacity. Six years later, the CSL practicum brings 40 students to the home for nine hours each in the winter semester. Each year the students from this course contribute over 360 volunteer hours for recreation and meal assist programs.

Both Ann and Margaret have a lot of autonomy in their positions and in managing the CSL initiative, which 
requires no additional funding support. Ann and Margaret are dedicated to the program because they see it is beneficial to all those involved. Residents and their families feel the students are helpful and bring positive energy to the home, and they enjoy the variety the students bring to their regular programs and activities.

The staff believe the CSL/CUP is worth the extra effort to help orient the students to the residents and daily operations. Getting residents to programs becomes more efficient with the students, and programs become much more manageable. This makes life more engaging and comfortable for residents and easier for their caregivers.

The wider community benefits from this initiative when there are events organized outside of the home. For example, a group of students from the course organized a trip to a university hockey game for residents who were interested and able. In this instance the wider community experienced students as caring, professional members of their community and long-term care residents as participating community members.

\section{Example 2: Farmers' Market CSL/CUP_contributing to a healthy and vibrant community}

When Barb Anderson started as director of the School of Nutrition and Dietetics, she prioritized developing a relationship with the Wolfville Farmers' Market and Kelly Marie Redcliffe, the market's manager. After two years of developing a trusting relationship, a CSL initiative called Kitchen Wizards was created. Kitchen Wizards, now in its eighth year, engages around 65 students a year in a food commodities course. The initiative introduces children to in-season local fruits and vegetables through a taste testing experience that gives them purchasing power to buy a local fruit or vegetable with a three dollar voucher after participating in the tasting.

This initiative is designed for first-year students, framing their degree as experiential and community focused. The students gain a sense of ownership and connection to the market and believe the program is having an impact on the participating children and families. The families that participate in the program think it is a creative way to introduce kids to new foods, and it usually results in the child interacting with a local farmer, connecting them directly to their food. This interaction is memorable for the farm vendor as well, as they enjoy teaching the kids about their produce. When a family is committed to participating in the program, the child can clearly articulate the benefits of eating in season foods from their community. To extend their reach to families who may not frequent the market, a partnership with a nonprofit childcare center was formed. The center brings school-aged children from diverse cultural and socio-economic backgrounds to the market to participate in the program. The educators believe this experience impacts the children's willingness to try new foods and their connection to the market.

The relationship between the Wolfville Farmers' Market and School of Nutrition and Dietetics has major ripple effects on both organizations and the local community. For example, Kelly Marie often employs students in various market positions, and Barb co-chaired the market's Good Food Hub advisory board, which has allowed them to work together on multiple community projects. Kelly Marie is given a lot of autonomy from her board and has a very engaged staff, who all support the vision of the initiative and the partnership, and Barb has the support of her school. 


\section{Example 3: Adapted Physical Activity CSL/CUP_play and connectivity through physical activity}

The Acadia University S.M.I.L.E. (Sensory Motor Instructional Leadership Experience) program, established in 1982, is an academic-based, volunteer-driven program that offers children, youth, and adults with varying abilities a unique physical activity experience to improve their overall motor development. Dr. Roxanne Seaman, a professor in kinesiology, has been the director of S.M.I.L.E. since 2002 and works closely with public schools and families in the local area to bring 280 participants to S.M.I.L.E. each year. S.M.I.L.E. also involves coordinating 450 Acadia student-volunteers. Eighty of the student-volunteers are part of a course that Roxanne teaches in kinesiology. A large portion of this course is a CSL component involving the students as instructors in one of the S.M.I.L.E. program days. There are four official program days serving different purposes and demographics. Roxanne oversees all the programs, with help from a part-time coordinator.

The program started small when an Acadia professor teamed up with a high school teacher to develop a swim program for students with special needs, which engaged Acadia students as volunteers. As the program grew, the primary community partner became the school board, although practically the resource teachers at the now 17 schools that send students to S.M.I.L.E. are really Roxanne's principal partners. The resource teachers work with the school's staff to select students for S.M.I.L.E., and they provide information about the students to Roxanne. The resource teacher or educational assistant accompanies students each week to the program, and they provide support when needed to the student-volunteers. The resource teachers report that students return to school from S.M.I.L.E. ready to learn and feeling positive about themselves and their abilities. Participants are exposed to physical activities based on their interests and abilities, which for some has opened opportunities for them in community recreation and competitive sport. The line of communication between each resource teacher and Roxanne is always open, and in many cases the relationship is well established.

All the family members, participants, teachers, and student-volunteers refer to S.M.I.L.E. as a family and feel strongly that the relationship formed between the participant and the student-volunteer is the most significant component of the program. However, the resource teachers interviewed felt that their students did not have the same sense of community unless they continued in the program throughout their schooling with some continuity with a student-volunteer.

Arguably, the biggest benefactors of the S.M.I.L.E. family are the student-volunteers, particularly those committed to volunteering throughout their degree. They become part of a sub-culture on campus. Many studentvolunteer alumni of the program credit S.M.I.L.E. for their career choices and their dedication to civic engagement.

\section{Analysis and Discussion}

There are commonalities between these CUPs that are also supported in the literature. The results demonstrate that the developmental process of any CSL/CUP is unique, but each process can be broadly described as an interactive process involving the entry and development of the CSL/CUP, the co-creation of the initiative, and 


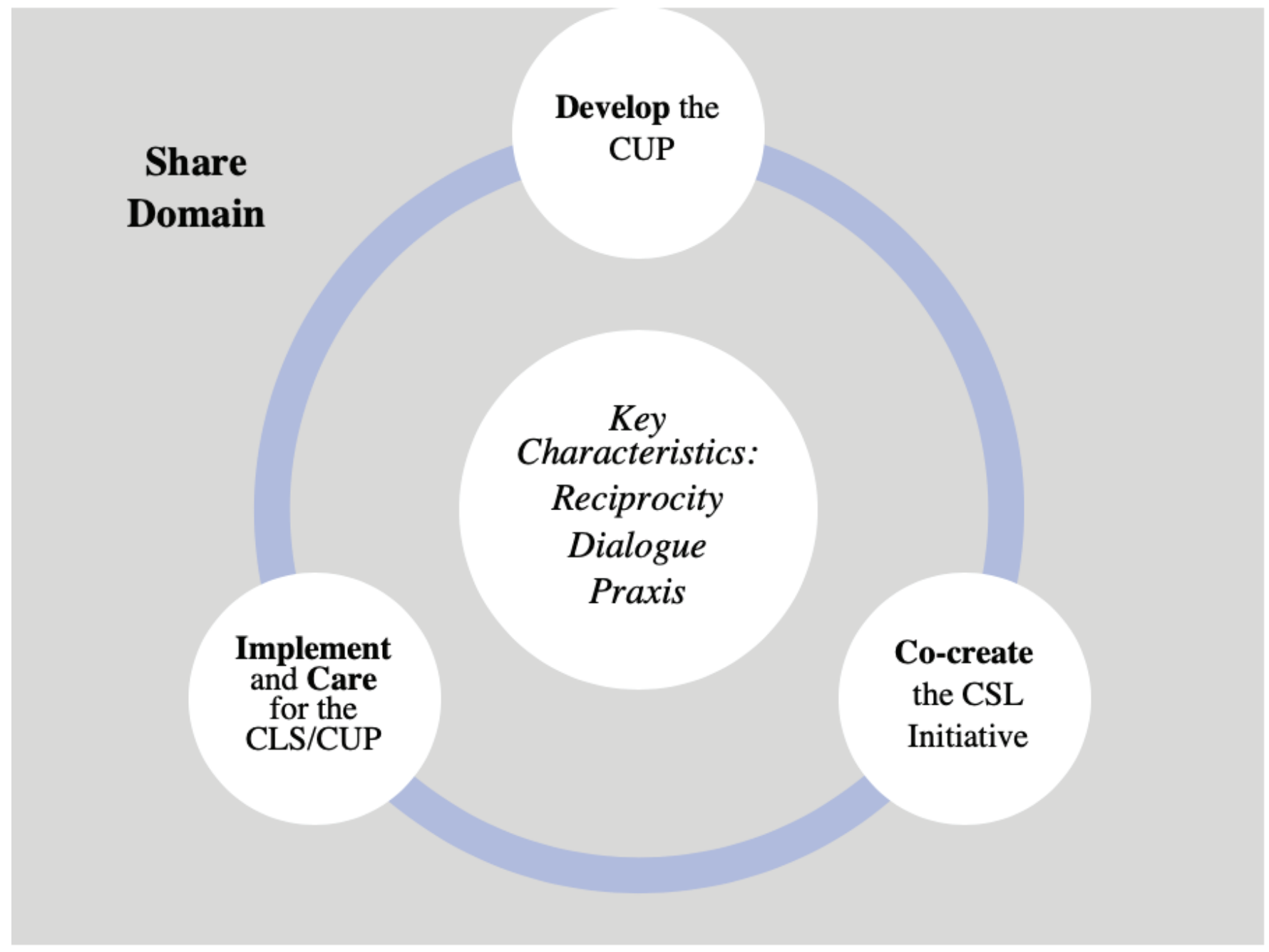

Figure 1. The CSL/CUP process model showing processes and characteristics of long-term CUPs that generate community-valued development outcomes.

then its implementation and care over time. There are also two phenomena that influence the CSL/CUP process. The first is the shared domain in which the partnership is situated, and the second are the key characteristics that influence the process. Figure 1 depicts the three stages of the process in a circle: (a) developing the CUP, (b) co-creating the CSL initiative, and (c) implementing and caring for the initiative. The process is contained by a box that represents the shared domain, which is the community issue to which the partners are committed. Within the heart of the diagram, the influencing characteristics are those that emerged from the literature and the three cases: reciprocity, dialogue, and praxis. These characteristics guide the partners throughout each stage of the process. The CSL/CUP process model is dynamic and specific to each initiative. This model is not a blueprint to success but a depiction of what was found in this study's investigation into three CSL/CUPs.

Although these components are described separately, in practice they are interconnected and may not be explicit, distinct, or linear. Although some CSL/CUPs may follow a linear path, from entry, development, implementation to exit, long-term partnerships cycle through the stages depending on changes in the local environ- 
ment and community, the institutional constraints or opportunities, and the changing community and student assets and needs. The following sections elaborate on the shared domain, process stages, and key characteristics of the CSL/CUP model, using the findings from this study and current literature.

\section{Identifying a Shared Domain}

The term shared domain comes from the social learning theory literature, describing one of the key elements of communities of practice. "A community of practice is a group of people who share a concern or a passion for something they do and learn how to do it better as they interact regularly” (Wenger, 1998, p. 1). The shared domain refers to the common concern/passion that brings the community of practice together, which guides their learning and gives meaning to their actions (Wenger, 1998). All three CSL/CUPs in this study had a shared domain, which they described as their common interests and commitments to their field. The Aging Well CSL/ CUP was formed based on Ann and Margaret's interests in increasing the quality of life of seniors through a holistic model of wellness as well as enabling nursing homes to be places to experience civic responsibility. The Adapted Physical Activity CSL/CUP relies on partnering with teachers and students who share a passion for adapted physical activity and who are committed to providing high-quality programs that celebrate diversity, human dignity, and inclusion. At the core of what motivates Kelly Marie and Barb from the Farmers' Market CSL/CUP is their commitment to a healthy, vibrant community through understanding local, community food systems. Kelly Marie articulated the importance of this shared domain when she stated:

I very much believe in the vision, which is to better the health and vibrancy of our community and that's where the partnership makes sense, because Barb has a vision to increase the health of the community. I think having that shared context and vision, even though we have different motivations, makes it easy for there to be win-wins.

Margaret and Ann and Kelly Marie and Barb had previous experience with each other and were aware of each other's commitment to the shared domain. This allowed them to confidently enter into this partnership and develop a sustainable initiative. For the Adapted Physical Activity CSL/CUP, there have been many people invested in the shared domain over its 38 years, and because it is such a well-branded program in the community, it draws community members to it who share similar community interests.

The shared domain becomes the container for the process. Each partner is committed to the partnership and process because the shared domain is their passion, not their job. For example, Kelly Marie said that her job is to increase patrons and revenue for market vendors, and for Barb one of her teaching objectives is to teach students how to effectively communicate messages about food commodities to the public. But their passion for a healthy, vibrant community through food is what commits them to the partnership. In the literature, Gazley et al. (2013) agree that all partners need to be accountable for improving community welfare, so that the service-leaning initiative does not just serve student learning but also meets a community need. Wills et al.'s (2010) case study on 
a community garden project brought together multiple nonprofit organizations and a local university because of their shared domain to address poor nutrition in their community. Similarly, Rutherford et al.'s (2011) case study on a CSL/CUP at a homeless shelter described the importance of the partnership being grounded in social justice and desire to meaningfully address poverty and homelessness. This shared domain meant that "the individuals involved were willing to take risks and push the boundaries of their highly bureaucratic institutions and traditional professional practices on the basis of their common professional commitment to social justice" (Rutherford et al., 2011, p. 491). If a CSL/CUP is not built on a shared domain for a community issue, it runs the risk of reducing the engagement to a public relations function for the university, in which the community serves as a recipient, frequently leading to short-term engagement (Saltmarsh et al., 2009).

\section{The CSL/CUP Process}

The CSL/CUP process is complex with many nuances but has been condensed to three overarching stages: (a) developing the partnership, (b) co-creating the CSL initiative, and (c) implementing and caring for the CSL/ CUP. However, some CSL/CUPs develop the partnership and the CSL initiative at the same time or the CSL initiative first. For example, the Adapted Physical Activity CSL/CUP developed the initiative first and took years to develop the relationship with the school board and then the schools, continually adapting and expanding the CSL component along the way. The Aging Well and the Farmers' Market CSL/CUPs both developed the partnership first before establishing their initiatives. Either way, all the partnerships, through reciprocity, open dialogue, and praxis, continue to develop their partnership and the CSL initiative, making it a cyclical process. With this in mind, each of the three stages are described separately below.

Stage 1: Develop the partnership. A study that involved 99 experienced community partners found that the CUP relationship is foundational to the CSL experience (Sandy \& Holland, 2006). Developing a solid foundation in which to build a working relationship and a CSL initiative is a critical part of long-lasting, mutually beneficial CSL/CUPs (Austin, 2010; Davidson et al., 2010; Oberg De La Garza \& Moreno Kuri, 2014; Rosing \& Hofman, 2010). It is challenging to identify a set of overarching practices for this development stage, given the complexity and idiosyncrasies of each CSL/CUP; however, there are two common practices that seem to be consistent within the literature and in the three CSL/CUPs in this study: developing shared values and developing partnership goals.

Shared values. All the principal partners in the three CSL/CUPs spent time discussing their shared values as important to the development of their partnership. Shared values are distinct from a shared domain, which is the social issue or interest that brings the partners together regardless of individual values. It is, however, important for the partners to be aware of one another's individual or organizational values when entering into partnership. This helps to explicitly recognize positions of power and to develop the trust and respect that is key to a successful partnership (Cook, Hayden, Bryan, \& Belford, 2016). In this study, the principal partners expressed similar individual values to one another, which made the entry into their partnership easier and the building of shared values straightforward. This calls attention to the lack of diversity among the principal partners in the three 
CSL/CUPs, all of whom identify as female, white, university-educated professionals between the ages of 45 and 60. The faculty all approach their CSL/CUP similarly in that they put little emphasis on a research agenda relative to promoting student and community outcomes. Other values that cross all six principal partners are their commitments to health and wellness and a strong work ethic. Another common value that weaves through all of the principal partners' stories is humility and gratitude for their partner and their role in the community. "Humility - an intentional acknowledgement of one's modest, humble role in the larger world-serves as the essential currency of respectful, meaningful partnerships as it inherently places the emphasis on the greater good rather than on personal ego" (Stanlick \& Sell, 2016, p. 82).

That the partners shared these similar values before engaging in the partnership enabled them to easily develop shared values for their CSL/CUP. This contrasts with other research that indicates that having the same individual values is not necessary as long as there is a shared domain and a willingness to work together (Austin, 2010).

Mutual trust and respect are two shared values that seem to transcend most CSL/CUPs regardless of their level of diversity (Austin, 2010; Costandius et al., 2014; Rosing \& Hofman, 2010). All three partner groups in this study discussed mutual trust and respect as an important value of their partnership. When asked how they demonstrate this, all three CSL/CUP partners described their commitment to open dialogue, which was established early on. Similarly, Austin (2010) and Oberg De La Garza and Moreno Kuri (2014) found that good communication practices are fostered by dedicating time to relationship building that focuses on equity and trust.

Another shared value was student engagement. The faculty in this study were highly invested in student learning outcomes and agreed that experiential learning through community engagement was a very valuable pedagogical approach. The CSL/CUP community partners also discussed their commitment to university student learning through community engagement. This was also documented by Worrall (2007), whose 40 study participants, representing 12 community-based organizations, were committed to student education through their partnership with the university.

As a final note, the partners in this study agreed that it is important to recognize that there will be differences in priorities between the university and the community-based organization regardless of how similar the CSL/ CUP partners' values are. Being aware of this helped the partnership establish shared values and goals, which leads to the next common practice, setting shared goals.

Partnership goals. Developing and committing to shared goals is an important part of developing the partnership (Austin, 2010; Oberg De La Garza \& Moreno Kuri, 2014; Valaitis et al., 2016). This includes recognizing and incorporating one another's missions, goals, and capacities into the planning phase of the partnership (Gazley et al., 2013). All the principal partners in this study expressed very clear shared goals that incorporated one another's organizational goals. This was articulated by Margaret in her interview:

For Ann, the goal [for the students] is to come and have an experience with the residents, so they can learn about the aging process. [For the home], our goal is to increase programs for residents. With [students] we can have four programs where without them we can only have one. (The overarching goals) for both of us are about teaching and increasing holistic wellness for students, residents, and our community. 
All the CSL/CUP partners discussed the importance of defining and committing to their CSL/CUP goals as key to their success but also the importance of having a deep understanding and commitment to one another's programming and teaching goals.

Stage 2: Co-creation of the community service-l earning initiative. CSL initiatives that come from a co-created process between the community organization and the university are more likely to produce mutually beneficial outcomes, compared to initiatives that are developed solely by the university (Stanlick \& Sell, 2016). In fact, "good intentions without consideration of community voice can create damaging power structures" (Stanlick \& Sell, 2016, p. 81). If the two partners see themselves as committed citizens who care about a certain domain and come together, utilizing their community resources and assets, the power dynamic can be balanced. Their roles become multifaceted and empowered, leaving "behind the notion of community-campus partnerships as binaries that often devalue half of the partnership," the half that is the community (Stanlick \& Sell, 2016, p. 81). This co-created process honors "local community knowledge and academic knowledge, which leads to collaborative knowledge construction” (Saltmarsh et al., 2009, p. 9).

The non-binary partnership and commitment to co-creation through a shared community domain unites citizens as equal partners. This is exemplified by the Farmers' Market CSL/CUP. Kelly Marie and Barb spoke of the development stage of Kitchen Wizards as a meaningful collaboration that was based on reciprocity. Both partners invested time, creative energy, and organizational resources into the development of the program, and they are grateful to the other for their contributions. The Aging Well CSL/CUP also co-created their initiative. Ann did not know what the CSL initiative would look like before she reached out to Margaret, and she was happy for Margaret to decide how the nursing home could best utilize 40 student volunteers. Ann's only requirement of the initiative was to expose the students to the aging process, which would help to illuminate what the students were learning in class. Through dialogue they decided that the initiative would be program based and nine hours would be an appropriate amount of time to expect students to volunteer outside of their regular course hours. The co-creation of these initiatives support the findings of other research (see Andrée et al., 2014; Austin, 2010; Gazley et al., 2013; Marullo et al., 2009).

The three CSL/CUPs faculty members did not perceive themselves as the "expert." For example, both Farmers' Market CSL/CUP partners articulated the inherent power imbalance that the university partner can hold and how that can impact partnerships but felt very confident that their relationship was equitable through the sharing of resources, leadership, and liability. The ability to co-create the CSL/CUP allows universities to demonstrate their commitment and shared responsibility to civic engagement (Bartleet, Sunderland, \& Carfoot, 2016; Schaffer et al., 2015; Shannon \& Wang, 2010).

Stage 3: Implementation and care of the CSL/CUP. The implementation and care of the CSL/CUP initiative is about nurturing the partnership during this action-oriented stage of the process. This stage can become overwhelming as implementation can demand a lot of time and energy from both the faculty and the community partner. However, all the partners discussed how incorporating opportunities for feedback and reflection with each other, the students and the community participants, has been integral to their long-term success. This is supported by Naidoo and Devnarain (2009), who state that "consultation with all partners is required in order 
to modify service learning modules to respond to the contextual challenges during all stages of implementation” (p. 950). Roxanne engages in formal reflections with student-volunteers on a weekly basis. Her communication with the community, although not formal, is ongoing:

Although no formal reflection is done between the schools and S.M.I.L.E., I check in with the principals to see if I can make it easier, better, or different. I am always looking for feedback. I go to veteran resource teachers for advice, I want to make sure we are doing our best. Any issue that happens is dealt with immediately because we (parents, educational assistants, university student volunteers, resource teachers) see each other each week, face to face.

Many studies found that nurturing the partnership during the implementation of the CSL initiative was essential to community-valued development outcomes (Austin, 2010; Oberg De La Garza \& Moreno Kuri, 2014). One study identified that it was the responsibility of the faculty to maintain this open communication and build trust with the community-based organization (Hansen, 2015), which relates to the Adapted Physical Activity CUP and Roxanne's role. Roxanne is seen by the community and her students as the visionary leader for S.M.I.L.E. Roxanne's values spread to everyone she works with at S.M.I.L.E., and she is known for her unwavering commitment to the program. For the Farmers' Market CSL/CUP and the Aging Well CSL/CUP, however, this nurturing seems to be shared between the two partners more equally. This difference could be because in the Adapted Physical Activity CSL/CUP, Roxanne, as the faculty partner, is facilitating the students as well as hosting the program on campus, giving her more power and ownership over the partnership. In contrast, the two other CSL/CUPs seem to have more equitable power distribution because the faculty is facilitating the students, and the community partner is facilitating the community space for the program, meaning there are more shared resources and a sense of shared ownership and reliance on each other.

\section{Commitment to Key Characteristics}

As the final element of the conceptual model, three key characteristics emerged as critical to CSL/CUPs, both from the three examples in this study and in the literature: reciprocity, dialogue, and praxis. These three characteristics were at the heart of the CSL/CUP processes, guiding the actions and interactions of the partners in each of the process stages. Although reciprocity, dialogue, and praxis are interrelated characteristics, this section describes and analyzes each characteristic separately in relation to the three case study examples.

Reciprocity. Jameson, Clayton, and Jaeger (2010) describe reciprocity as being thick (transformational and co-created partnerships) or thin (mutual and transactional partnerships). Janke (2013), however, defines a spectrum of reciprocity that goes from thick to thin, from community engagement working with the community to service provided for the community to collecting research on the community. In this study, the Farmers' Market CUP exemplifies thick reciprocity, as Kelly Marie and Barb are committed to "mutual exchange of ideas, the collaborative generation of knowledge, shared power, and joint ownership of the full scope of work processes 
and outcomes” (Janke, 2013, p. 12). Both Kelly Marie and Barb reflected on their deep commitment to their reciprocal relationship:

You have to give a lot to get a lot back-you have to be willing to step in. Investment in the relationship with time, money, ingredients, expertise, letters of reference, mentorship. You need to care about the person that you are connecting with, so you are willing to work through things, address issues. It is very clear to me that Barb only wants to do a program that serves the market and that benefits her students and I am only interested in doing programing that has value ... we want the same thing. Not a stitch of power concerns. (Kelly Marie Redcliffe)

We were really cognizant of building something that continues, not just a one-time initiative, and how do we do it in a way that is thoughtful, respectful and builds relationships, meets the needs of the market, builds community between the market and the School of Nutrition. We respect each other's contributions and communicate openly. We go for lunch and meet just because ... I think (our relationship) is equal, I think Kelly Marie would say it is equal too. Because we have trust. I think if we ran into a real big wall, we could deal with it. (Barb Anderson)

Although the Adapted Physical Activity CSL/CUP and the Aging Well CSL/CUP have components of thick reciprocity, such as the co-creation of the CSL initiative, they would be closer to the center of the spectrum, as both are providing services for the community. The CSL initiative for the Aging Well CSL/CUP is an end in itself, and Margaret and Ann do not tend to go beyond the initiative. However, their partnership is collaborative, and they have joint ownership of the project, two characteristics of thick reciprocity (Janke, 2013). Similarly, the Adapted Physical Activity CSL/CUP engages in a collaborative process with schools and student-volunteers to ensure they are providing the best service possible for their participants. This comes from Roxanne's collaborative leadership style and openness to continually develop S.M.I.L.E. However, the majority of the power still remains with the program and the university, which serves the community.

Dialogue. Dialogue and respectful communication are discussed frequently in the CSL/CUP literature (Gazley et al., 2013; Marullo et al., 2009; Oberg De La Garza \& Moreno Kuri, 2014). Dialogue is the heart of Freire's (1993) critical consciousness process, which Ledwith (2015) summarizes as "mutual, respectful communication between people, engaging the heart and mind, the intellect and emotions. ... It involves horizontal communication between equals who are mutually engaged in a process of critical inquiry” (p. 57). For the three CSL/CUPs in this study, their level of commitment to a dialogical process was revealed through the partners' communication style. Kelly Marie and Barb are both reflective and conscientious communicators; they engage in open dialogue throughout the year even though the CSL initiative only runs in the fall. They believe their CSL initiative is an opening for further dialogue on ways that their two organizations can work together to 
contribute to a healthy, vibrant community and address important community food issues. Roxanne and her partner resource teachers do not formally engage in dialogue, but when they do have the opportunity to chat, they have deep conversations about inclusion and equity for children who have been labeled by the school system. Margaret and Ann, whose CSL initiative is perhaps the most similar to a transactional partnership (Enos \& Morton, 2003), had not formally engaged in a dialogical process until they met together for this study's interview process. They acknowledged at the end of their joint interview that they learned a lot about how the other was experiencing the CSL/CUP, and it helped to develop the relationship piece of what they acknowledge as an already very successful CSL/CUP.

Praxis. Praxis, a common term in educational theory, was developed by Freire (1993), who believed that it was not enough to gain knowledge of social reality simply through dialogue but that a process of action and critical reflection should be incorporated into the educative process. "Praxis is the unity of theory and practice that comes together in action and reflection" (cited in Ledwith, 2015, p. 58). This unity of action and critical reflection became an important theme throughout the interview process with the faculty partners, community partners, and students. In all three CSL/CUPs, the faculty engaged with the students in praxis through guided reflections, in-class discussions, and written assignments that related to their experiences. All three faculty also spoke about their own learning and development as part of the partnership and their engagement with students during these guided reflections. Kelly Marie and Barb, from the Farmers' Market CSL/CUP, deliberately engaged in praxis with each other, their students, and staff, given their theoretical background in community development. Barb has a strong background in asset-based community development and Freirean theory, which guides her practice in this CUP. Kelly Marie saw one of Barb’s roles as leading the CSL/CUP through a collaborative and reflective practice and her own role as balancing process and action. Roxanne and Ann, although community minded and intuitively engaged in a reflective practice, particularly with their students, did not engage in praxis to the same degree with their community partners. This lack of praxis led to more place- and activity-based CSL initiatives for both of these CUPs. Ann and Margaret's initiative, for example, has resulted in a CSL initiative that has not evolved much from its original service-based idea. Opportunities to engage in a critical reflective process with partners is necessary for transformation and social change. Stanlick and Sell (2016) believe that thick reciprocity and Freire's vision of dialogue and praxis have the potential to drive social and civic change (Stanlick \& Sell, 2016). These three characteristics are intertwined, and if woven together throughout the CSL/CUP process, can create long-term community-valued development outcomes.

\section{Conclusion}

From the literature review and three case examples, a CSL/CUP process model emerged, comprising a shared domain, three process stages, and three characteristics. Within a shared domain, the three stages of CSL/CUPS are the development of the CUP, the co-creation of the CSL initiative, and the implementation and care of the CSL/CUP. The effectiveness of this process is impacted by the extent to which reciprocity, dialogue, and praxis 
characterize the partnership. This emergent model adds to the understanding of the interconnected characteristics and processes that influence community outcomes. Given the limited scope of this research, this model's validity requires additional study. A study that assesses the model by investigating CSL/CUPs at other institutions would expand understanding of how the processes and characteristics of CSL/CUPs impact the outcomes. It would be valuable to test this model on CSL/CUPs that involve more diverse partnerships and to better understand how the organizations that the partners represent influence this model. For example, how do broader institutional or community organization practices support or undermine the shared domain, the processes, and the characteristics of the CSL/CUP? It also begs the question, How might successful CSL/CUPS be systematized and incentivized by their organizations, particularly universities who often use community engagement as a promotional tool? In addition, how do university administrations understand the complexity of long-term CSL/CUPs and their role in ensuring community-valued development outcomes?

Engaging in a long-term CSL/CUP that contributes to community-valued development outcomes requires a tremendous commitment from the community partner and the faculty partner. All three CSL/CUPs in this study were located in the same community as the university, and all the partners felt personally connected to the local community as community members. They all were committed to bettering their community, using their personal and professional assets and resources to do so. A study that compares the commitment of these partners to their colleagues in similar fields who do not engage in CSL/CUPs would help to further understand what motivates these highly committed and community-minded individuals.

\section{References}

Andrée, P., Chapman, D., Hawkins, L., Kneen, C., Martin, W., Muehlberger, C., . . \& Stroink, M. (2014). Building effective r elationships for community- engaged scholarship in C anadian food s tudies. Canadian Food Studies/La Revue Canadienne Des études Sur L'alimentation, 1(1), 27-53. doi:10.15353/cfs-rcea.v1i1.19 Apatu, E. J. I., Slawson, D., \& Gonzalez, M. A. (2013). Combating childhood obesity through a young adultled S.O.C.C.E.R. program in Northeast Tennessee. Children, Youth and Environments, 23(3), 184-193. doi:10.7721/chilyoutenvi.23.3.0184

Astin, A. W., Vogelgesang, L. J., Ikeda, E. K., \& Yee, J. A. (2000). How service learning affects students. Higher Education, 144, 361-395. Retrieved from https://digitalcommons.unomaha.edu/slcehighered/144

Austin, D. (2010). Confronting environmental challenges on the US-Mexico border: Long-term communitybased research and community service learning in a binational partnership. Journal of Community Practice, 18(2-3), 361-395. doi:10.1080/10705422.2010.490112

Bargerstock, B. A., \& Bloomgarden, A. (2015). Community partnerships and impacts. The International Journal of Research on Service-Learning and Community Engagement, 4(1), 99-100. Retrieved from http://journals.sfu.ca/iarslce/index.php/journal/article/view/255

Bartleet, B.-L., Sunderland, N., \& Carfoot, G. (2016). Enhancing intercultural engagement through service learning and music making with Indigenous communities in Australia. Research Studies in Music Education, 38(2), 173-191. doi:10.1177/1321103X16667863 
Blackmore, C. (2010). Managing systemic change: Future roles for social learning systems and communities of practice? In C. Blackmore (Ed.), Social Learning Systems and Communities of Practice (pp. 201-218). London, UK: Springer.

Bloomgarden, A. H. (2017). Out of the armchair: About community impact. The International Journal of Research on Service-Learning and Community Engagement, 5(1), 21-23. Retrieved from http://journals.sfu. ca/iarslce/index.php/journal/article/view/307

Blouin, D. D., \& Perry, E. M. (2009). Whom does service learning really serve? Community-based organizations' perspectives on service learning. Teaching Sociology, 37(2), 120-135.

Bringle, R. G., Clayton, P. H., \& Price, M. F. (2009). Partnerships in service learning and civic engagement. Partnerships: A Journal of Service-Learning and Civic Engagement, 1(1), 1-20. Retrieved from http://libjournal. uncg.edu/prt/article/view/415/228

Bucher, J. (2012). Old and young dogs teaching each other tricks: The importance of developing agency for community partners in communitylearning. Teaching Sociology,40(3),271-283. doi:10.1177/0092055X12442498

Carney, J. K., Maltby, H. J., Mackin, K. A., \& Maksym, M. E. (2011). Community-academic partnerships: How can communities benefit? American Journal of Preventive Medicine, 41(4), S206-S213. doi:10.1016/j. amepre.2011.05.020

Chupp, M. G., \& Joseph, M. L. (2010). Getting the most out of service learning: Maximizing student, university and community impact. Journal of Community Practice, 18(2-3), 190-212. doi:10.1080/10705422.2010.4 87045

Cook, A. L., Hayden, L. A., Bryan, J., \& Belford, P. (2016). Implementation of a school-family-community partnership model to promote Latina youth development: Reflections on the process and lessons learned. The International Journal of Research on Service-Learning and Community Engagement, 4(1), 101-117. Retrieved from https://journals.sfu.ca/iarslce/index.php/journal/article/view/189/123

Costandius, E., Rosochacki, S., \& le Roux, A. (2014). Critical citizenship education and community interaction: A reflection on practice. The International Journal of Art E̊ Design Education, 33(1), 116-129. doi:10.1111/ j.1476-8070.2014.01773.x

Cronley, C., Madden, E., \& Davis, J. B. (2015). Making service-learning partnerships work: Listening and responding to community partners. Journal of Community Practice, 23(2), 274-289. doi:10.1080/10705422 .2015 .1027801

Davidson, W. S., Jimenez, T. R., Onifade, E., \& Hankins, S. S. (2010). Student experiences of the adolescent diversion project: A community-based exemplar in the pedagogy of service-learning. American Journal of Community Psychology, 46(3-4), 442-458. doi:10.1007/s10464-010-9337-6

Dunkel, F. V., Shams, A. N., \& George, C. M. (2011). Expansive collaboration: A model for transformed classrooms, community-based research, and service-learning. NACTA Journal, 55(4), 65-74.

Eckerle Curwood, S., Munger, F., Mitchell, T., Mackeigan, M., \& Farrar, A. (2011). Building effective community-university partnerships: Are universities truly ready? Michigan Journal of Community Service Learning, 17(2), 15-26.

Enos, S., \& Morton, K. (2003). Developing a theory and practice of campus-community partnerships. In B. 
Jacoby \& Associates (Eds.), Building partnerships for service-learning (pp. 20-41). San Francisco, CA: JosseyBass.

Freire, P. (1993). Pedagogy of the oppressed. New York, NY: Continuum.

Gazley, B., Bennett, T. A., \& Littlepage, L. (2013). Achieving the partnership principle in experiential learning: The nonprofit perspective. Journal of Public Affairs Education, 19(3), 559-579.

Gerstenblatt, P., \& Gilbert, D. J. (2014). Framing service learning in social work: An interdisciplinary elective course embedded within a university-community partnership. Social Work Education, 33(8), 1037-1053. doi:10.1080/02615479.2014.935731

Goemans, M. (2016, September 2). What I've learned so far: An initial review of scholarly literature on community impact in CCE. Retrieved from https://carleton.ca/communityfirst/2016/what-ive-learned-so-far-aninitial-review-of-scholarly-literature-on-community-impact-in-cce/

Guba, E. G., \& Lincoln, Y. S. (1989). Fourth generation evaluation. Newbury Park, CA: Sage.

Hansen, A. M. W. (2015). A qualitative study of community-university partnerships that support psychosocial occupational therapy. Occupational Therapy in Mental Health, 31(2), 113-143. doi:10.1080/01642 12X.2015.1031358

Hlalele, D., Manicom, D., Preece, J., \& Tsotetsi, C. T. (2015). Strategies and outcomes of involving university students in community engagement: An adaptive leadership perspective. Journal of Higher Education in Africa/Revue de l'enseignement Supérieur En Afrique, 13(1-2), 169-193.

Howard, A. L. (2010). Engaging the city: Civic participation and teaching urban history. Journal of Urban History, 36(1), 42-55. doi:10.1177/0096144209349883

Jamal, T., Taillon, J., \& Dredge, D. (2011). Sustainable tourism pedagogy and academic-community collaboration: A progressive service-learning approach. Tourism and Hospitality Research, 11(2), 133-147. doi: $10.1057 /$ thr.2011.3

Jameson, J. K., Clayton, P. H., \& Jaeger, A. J. (2010). Community-engaged scholarship through mutually transformative partnerships. In L. M. Harter, J. Hamel-Lambert, \& J. L. Millesen (Eds.), Participatory partnerships for social action and research (pp. 259-277). Dubuque, IA: Kendall Hunt.

Janke, E. (2013). Increased community presence is not a proxy for reciprocity. EJournal of Public Affairs, 2(2), 1-23. doi:10.21768/ejopa.v2i2.13

Janke, E. M., \& Clayton, P. H. (2012). Excellence in community engagement Ev community-engaged scholarship: Advancing the discourse at UNCG (Vol. 1). Greensboro, NC: University of North Carolina at Greensboro. Retrieved from https://communityengagement.uncg.edu/wp-content/uploads/2014/07/ Excellence-in-Community-Engagement-and-Community-Engaged-Scholarship-Volume-1-Advancing-the-Discourse-at-UNCG.pdf

Jovanović, A., \& Filipović, J. (2013). Spanish teacher education programs and community engagement. Hispania, 96(2), 283-294. doi:10.1353/hpn.2013.0056

Kearney, K. R. (2013). Impact of a service-learning course on first-year pharmacy students' learning outcomes. American Journal of Pharmaceutical Education, 77(2). doi:10.5688/ajpe77234 
Klein, P., Fatima, M., McEwen, L., Moser, S. C., Schmidt, D., \& Zupan, S. (2011). Dismantling the ivory tower: Engaging geographers in university-community partnerships. Journal of Geography in Higher Education, 35(3), 425-444. doi:10.1080/03098265.2011.576337

Krueger, R. A., \& Casey, M. A. (2014). Focus groups: A practical guide for applied research (5th ed.). Thousand Oaks, CA: Sage.

Lauckner, H., Paterson, M., \& Krupa, T. (2012). Using constructivist case study methodology to understand community development processes: Proposed methodological questions to guide the research process. The Qualitative Report, 17(13), 1-22.

Ledwith, M. (2015). Community development in action: Putting Freire into practice. Bristol, UK: Bristol University Press.

Marullo, S., Moayedi, R., \& Cooke, D. (2009). C. Wright Mills's friendly critique of service learning and an innovative response: Cross-institutional collaborations for community-based research. Teaching Sociology, 37(1), 61-75. doi:10.1177/0092055X0903700106

Merriam, S. B. (2007). Qualitative research and case study applications in education (2nd ed.). San Francisco, CA: Jossey-Bass.

Naidoo, B., \& Devnarain, B. (2009). Service learning: Connecting higher education and civil society-Are we meeting the challenge? South African Journal of Higher Education, 23(5), 935-952.

Northmore, S., \& Hart, A. (2011). Sustaining community-university partnerships. Gateways: International Journal of Community Research and Engagement, 4, 1-11.

Oberg De La Garza, T., \& Moreno Kuri, L. (2014). Building strong community partnerships: Equal voice and mutual benefits. Journal of Latinos and Education, 13(2), 120-133.

Pillard Reynolds, N. (2014). What counts as outcomes? Community perspectives of an engineering partnership. Michigan Journal Community Service Learning, 21(1), 79-90.

Prawat, R. S., \& Floden, R. E. (1994). Philosophical Perspectives on Constructivist Views of Learning. Educational Psychologist, 29(1), 37-48. doi:10.1207/s15326985ep2901_4

Rosing, H., \& Hofman, N. G. (2010). Notes from the field: Service learning and the development of multidisciplinary community-based research initiatives. Journal of Community Practice, 18(2-3), 213-232. doi:10.108 0/10705422.2010.490101

Rutherford, G. E., Walsh, C. A., \& Rook, J. (2011). Teaching and learning processes for social transformation: Engaging a kaleidoscope of learners. Journal of Teaching in Social Work, 31(5), 479-492. doi:10.1080/0884 1233.2011.614206

Saltmarsh, J., Hartley, M., \& Clayton, P. (2009). Democratic engagement white paper. New England Resource Center for Higher Education, 1-15. Retrieved from http://repository.upenn.edu/gse_pubs/274

Sandy, M., \& Holland, B. A. (2006). Different worlds and common grounds: Community partner perspectives on campus-community partnerships. Michigan Journal of Community Service Learning, 13(1), $30-43$.

Schaffer, M. A., Hargate, C., \& Marong, K. (2015). Engaging communities in nursing education. The Inter- 
national Journal of Research on Service-Learning and Community Engagement, 3(1), 1-16. Retrieved from http://journals.sfu.ca/iarslce/index.php/journal/article/view/112

Schwandt, T. A. (1994). Constructivist, interpretivist approaches to human inquiry. In N. K. Denzin \& Y. S. Lincoln (Eds.), Handbook of qualitative research (pp. 118-137). Thousand Oaks, CA: Sage.

Shalabi, N. (2013). Exploring community partners' perspectives of the nature of service-learning partnerships in Egypt. The International Journal of Research on Service-Learning and Community Engagement, 1(1), 80-91. Retrieved from http://journals.sfu.ca/iarslce/index.php/journal/article/view/26

Shannon, J., \& Wang, T. R. (2010). A model for university-community engagement: Continuing education's role as convener. The Journal of Continuing Higher Education, 58(2), 108-112. doi:10.1080/07377361003661499

Shields, S. L., Gilchrist, L. Z., Nixon, C. T., Holland, B. A., \& Thompson, E. A. (2013). An ecological approach to a university course that develops partnerships impacting health and wellness in K-12 schools and communities. Peabody Journal of Education, 88(5), 608-621. doi:10.1080/0161956X.2013.835177

Simons, H. (2009). Case study research in practice. London, UK: Sage.

Srinivas, T., Meenan, C. E., Drogin, E., \& DePrince, A. P. (2015). Development of the community impact scale measuring community organization perceptions of partnership benefits and costs. Michigan Journal of Community Service Learning, 21(2), 5-21.

Stake, R. E. (1995). The art of case study research. Thousand Oaks, CA: Sage.

Stake, R. E. (2006). Multiple case study analysis. New York, NY: The Guilford Press.

Stanlick, S., \& Sell, M. (2016). Beyond superheroes and sidekicks: Empowerment, efficacy, and education in community partnerships. Michigan Journal of Community Service Learning, 23(1), 80-84.

Suarez-Balcazar, Y., Harper, G. W., \& Lewis, R. (2005). An interactive and contextual model of communityuniversity collaborations for research and action. Health Education E Behavior, 32(1), 84-101. doi:10.1177/1090198104269512

Valaitis, R. K., Wahoush, O., Murray, N., Isaacs, S., Derbyshire, D., Semogas, D., \& Rolfe, S. (2016). Street smarts $\leftrightarrow$ book smarts: Three neighborhoods and one university school of nursing partnering for health. SAGE Open, 6(3), 1-16. doi:10.1177/2158244016656392

Weaver, R. G., Webster, C. A., Egan, C., Campos, C. M. C., Michael, R. D., \& Vazou, S. (2017). Partnerships for active children in elementary schools: Outcomes of a 2-year pilot study to increase physical activity during the school day. American Journal of Health Promotion, 32(3), 621-630. doi:10.1177/0890117117707289

Wenger, E. (1998). Communities of practice: Learning, meaning, and identity. Cambridge, UK: Cambridge University Press.

Wills, J., Chinemana, F., \& Rudolph, M. (2010). Growing or connecting? An urban food garden in Johannesburg. Health Promotion International, 25(1), 33-41. doi:10.1093/heapro/dap042

Wilson, A. M. (2016). The community project: Grounding global citizenship in The Hague. Transformations: The Journal of Inclusive Scholarship and Pedagogy, 26(2), 194-212. doi:10.5325/trajincschped.26.2.0194

Worrall, L. (2007). Asking the community: A case study of community partner perspectives. Michigan Journal of Community Service Learning, 14(1), 5-17. 


\section{Authors}

DR. MARY SWEATMAN is an Assistant Professor in Community Development at Acadia University in Wolfville, Nova Scotia, and a recent graduate of the Nova Scotia Inter-University Doctoral Program in Education Studies. Her teaching and research interests include community-campus partnerships, experiential learning, and equitable community spaces.

DR. ALAN WARNER is Professor Emeritus in Community Development and Environmental and Sustainability Studies at Acadia University in Wolfville, Nova Scotia. He has been designing, directing, and evaluating community-based, experiential education programs for more than 35 years with a wide range of learners.

Contributors: Kelly Marie Redcliffe and Barb Anderson from the Farmers' Market CSL/CUP, Margaret Coghill and Ann Dodge from the Aging Well CSL/CUP, and Dr. Roxanne Seaman and the S.M.I.L.E. community from the Adapted Physical Activity CSL/CUP. 